\title{
A PROMOCÃO DA EXPERIÊNCIA DOS UTILIZADORES COMO UM ESTIIIIULO A APRENDIZAGEM EM MUSEUS: um estudo exploratório
}

\author{
USERS AS A STIMULUS TO LEARNING IN MUSEUMS: \\ an exploratory study
}

\author{
André Pereira Pacheco ${ }^{1}$ \\ Maria Cristina Vieira de Freitas ${ }^{2}$ \\ Carlos Guardado da Silva ${ }^{3}$
}

\begin{abstract}
RESUMO
De forma geral, as comunidades tendem a manifestar um desejo inerente de interação com 0 património de modo a conhecer o seu passado e formar a sua identidade. As instituições culturais, como os museus, são vistas enquanto serviços de informação, que devem gerir os seus objetos informacionais de modo a comunicar eficiente e apelativamente o significado dos seus artefactos aos visitantes, proporcionando-Ihes através de uma narrativa contextualizada toda uma experiência de aprendizagem enriquecedora e memorável. No entanto, a experiência dos utilizadores é normalmente vista sob uma perspetiva da conceção de tecnologias. Este estudo procura alargar o conceito de experiência ao contacto do visitante com o espaço e contexto do museu. Para tal, procede-se a uma revisão de literatura para o presente estudo, de natureza qualitativa e exploratória, tendo por base pesquisas nas bases de dados de referência Web of Science e ProQuest com o fim de recuperar artigos científicos sobre a experiência dos utilizadores em museus. Enquanto resultado, o sistema tecnológico de informação é apontado como um elemento mediador entre a informação dos objetos e o conhecimento dos visitantes. Defende-se que os museus devem procurar afirmar-se como locais promotores de experiências pessoais de forma a promover o enriquecimento cultural dos visitantes. Embora esta ideia não seja necessariamente inédita, conclui-se que fatores mais ignorados como a tecnologia e o espaço devem constituir critérios-chave dessa afirmação.
\end{abstract}

Palavras-chave: User experience. Mediação. Museus. Ciência da Informação.

\section{ABSTRACT}

It is common for communities to exhibit an inner desire to interact with heritage in order to become acquainted with their past and shape their identity. Cultural institutions, such as museums, are posited as information services that must manage their information objects in a way that communicates efficiently and appealingly the meaning of their artifacts to the visitors, ensuring a memorable, pleasant and knowledgeable experience. However, user experience is normally understood of systems design. This study seeks to expand the concept of experience to the visitor's contact with the space and context of a museum. A qualitative literature review of the most relevant papers allows for an exploratory study based on a search in the references databases Web of Science and ProQuest with the aim of retrieving articles about user experience in museums. As a result, the information technology system is argued to be the mediating element between the information in objects and visitor's knowledge. It is stated that that museums should be consolidated as spaces that promote strong personal experiences in order to enhance the learning of visitors. Although this idea is not pioneer, it is concluded that more overlooked aspects such as technology and space should be considered key criteria of that consolidation.

Keywords: User experience. Mediation. Museums. Information Science.

Artigo submetido em 30/01/2020 e aceito para publicação em 07/07/2020

1 Doutorando em Ciência da Informação. Faculdade de Letras, Centro de Estudos Interdisciplinares do Século XX. Universidade de Coimbra, Portugal. ORCID https://orcid.org/0000-0002-1810-4866. E-mail: andrez.pacheco@gmail.com

2 Diretora do Mestrado em Ciência da Informação. Faculdade de Letras, Centro de Estudos Interdisciplinares do Século XX. Universidade de Coimbra, Portugal. ORCID https://orcid.org/0000-0002-8849-8792. E-mail: cristina.freitas@fl.uc.pt

3 Diretor do Mestrado em Ciências da Documentação e Informação. Faculdade de Letras, Centro de Estudos Interdisciplinares do Século XX. Universidade de Coimbra, Portugal. ORCID https://orcid.org/0000-0003-1490-8709. E-mail: carlosguardado@campus. ul.pt 


\section{INTRODUÇÃO}

A entrada fulminante das tecnologias no nosso estilo de vida levou os profissionais dos museus a temer que os museus virtuais viessem a substituir os museus físicos, fazendo com que as pessoas perdessem 0 interesse de visitar os museus tradicionais (MARTY, 2004). No entanto, isto não aconteceu, porque os museus não são apenas os espaços físicos, que um dia visitamos, locais com objetos de elevado valor simbólico e histórico reunidos em edifícios. Um museu é também uma memória, patrimonial e humana, um espaço privilegiado de diálogo e de comunicação, bem como um lugar de realização de experiências pessoais.

Os museus têm um papel fortemente experiencial pautado por sensações, envolvimento e um sentido estético (HOLBROOK, 2000; HASSENZAHL; TRACTINSKY, 2006). Esta dimensão é essencial para a aprendizagem dos visitantes porque as pessoas necessitam de uma representação dinâmica da história para melhor compreender a influência dos eventos passados na experiência pessoal. A investigação sobre a experiência dos utilizadores tem dado atenção a estas várias necessidades abordadas pela tecnologia, tais como o prazer (BLYTHE et al., 2003), a estética (LAVIE; TRACTINSKY, 2004) e o envolvimento cognitivo (AGARWAL; KARAHANNA, 2000). 0 enfoque é usualmente colocado nas dimensões emocionais, hedónicas e estéticas da experiência (HASSENZAHL; ROTO, 2007). No entanto, a investigação na experiência dos utilizadores é predominantemente orientada por uma matriz tecnológica de desenvolvimento das aplicações informáticas, tais como a criação de websites apelativos (PALLUD; STRAUD, 2014). Além dos raros desenvolvimentos das noções de experiência dos utilizadores na realidade dos museus, há uma notória ausência de estudos na literatura científica que abordem este conceito de uma forma sistémica, enquanto forma de mediação e aproximação entre os significados dos objetos e a aprendizagem dos visitantes. Por conseguinte, este estudo procura alargar o conceito de experiência ao contacto do visitante com o espaço e o contexto do museu.

Neste sentido, é motivado pelas seguintes questões de investigação: a) Pode a promoção de uma experiência positiva, enquanto um possível indicador de aumento do conhecimento do público-alvo, ser encarada como um fator-chave no sucesso de um sistema de informação museológico? b) Pode o conceito de 'experiência dos utilizadores' ser expandido para incluir não só o desenvolvimento das aplicações tecnológicas, mas também a experiência como um todo? c) Analogamente, pode o conceito de 'mediação' superar o sentido estritamente comunicacional entre humanos, para ser entendido ao nível da comunicação entre a informação de um artefacto e a sua receção por um observador? 
0 objetivo geral do estudo consiste em averiguar de forma exploratória as possibilidades de integração teórica dos conceitos de experiência do utilizador com as dimensões sistémicas de experiência pessoais em museus. De forma a responder a estas perguntas, foi adotada uma metodologia qualitativa assente numa revisão exploratória e crítica da literatura, recuperando os autores e os tópicos de análise mais pertinentes para as questões a explorar. Assim, na primeira parte, esclarece-se o posicionamento no âmbito da Ciência da Informação e abordam-se os conceitos de comunicação e mediação. Na segunda parte, o museu é caracterizado como um sistema e o seu objeto científico é definido. Na terceira parte, discute-se a importância da experiência dos utilizadores para uma aprendizagem fértil em museus. Por fim, apresentam-se as conclusões.

\section{METODOLOGIA}

A metodologia adotada assenta num estudo qualitativo de natureza exploratória da literatura (GIL, 2008, p. 26-32). A revisão narrativa da literatura (BRYMAN, 2016, p. 91) tem o objetivo de contextualizar o estudo nas correntes mais dominantes da literatura de forma a enquadrar e enriquecer a discussão dos conceitos extraídos. Dadas as questões de investigação, definiram-se como áreas de foco a Ciência da Informação (CI), a Teoria da Comunicação, a teoria sistémica e a experiência dos utilizadores, sob uma perspetiva museológica. A exploração inicial da literatura científica com 0 objetivo de delimitar um problema de investigação nestas três principais temáticas partiu das leituras de alguns dos autores de referência.

Para a Ciência da Informação, destacam-se Rafael Capurro, Armando Malheiro da Silva, Carlos Alberto Araújo e Michael Buckland. Para a teoria da comunicação, Claude Shannon e Warren Weaver. Para a teoria sistémica, Ludwig von Bertallanfy e as ramificações do conceito da Cl. Para o eixo temático de experiência dos utilizadores em museus, adotou-se a metodologia de investigação documental (BOWEN, 2009) que requer a constituição de um corpus documental que sirva de base ao estudo e a uma posterior análise de conteúdo (KRIPPENDORFF, 2004). Entendeu-se que uma fonte de informação adequada para este tipo de estudo seriam os artigos científicos, enquanto fontes privilegiadas de dados novos, consistentes e sujeitos a uma revisão pelos pares (MUELLER; CAMPELL0; DIAS, 1996).

De forma a consultar os artigos, realizaram-se pesquisas nas bases de dados de referência Web of Science (WoS) e ProQuest. As pesquisas em ambas bases de dados tiveram como critério comum a restrição de tipos documentais a "articles" com data de publicação até 15 de junho de 2018, a data da 
realização da pesquisa. No caso da WoS, a pesquisa incidiu sobre a 'Web of Science Core collection'. As pesquisas foram feitas com os seguintes especificações:

a) WoS: TS=("user experience" AND museu*) AND SU=(Library Science, Information Science)

b) ProQuest: 'museu*' AND 'user experience' IN 'All subjects \& indexing - SU'

Estas pesquisas tiveram como finalidade primária recuperar artigos científicos em Ciência da Informação, que discutissem a experiência dos utilizadores em museus, publicados até 15 de junho de 2018, data da realização do presente estudo. Neste sentido, incluiu-se como critério de pesquisa a palavra-chave "museu", com o objetivo de recuperar quaisquer artigos que contenham no tópico uma variante do termo 'museu'. Esta formulação permite recuperar tanto artigos em português que incluam o termo 'museu', 'museus' ou 'museológico', como artigos em inglês que se refiram a ‘museum' ou ‘museums'. Além disso, exigiu-se a coocorrência com o termo ‘user experience’ de forma a contextualizar os artigos na área de investigação pretendida.

Uma pesquisa inicial revelou a total ausência de artigos redigidos em português neste universo. Uma segunda pesquisa de artigos redigidos em inglês recuperou apenas seis artigos na Web of Science, e oito na ProQuest, que constituíram o corpus de textos usado na revisão de literatura sobre este assunto, num total de 14 artigos científicos (Tabela 1). Devido ao número relativamente diminuto da amostra, não se procedeu a uma organização formal dos dados exceto pela fonte de onde foram recuperados. Porém, como vantagem de uma amostra mais pequena, cada artigo científico recuperado foi analisado na integridade e incluído na revisão de literatura.

Quadro 1 - Bibliografia recuperada sobre experiência dos utilizadores em museus.

\begin{tabular}{|c|c|c|c|}
\hline Fonte & Autor & Ano & Título \\
\hline WoS-1 & Fleming-May, Rachel et al. & 2018 & $\begin{array}{l}\text { Experience assessment: designing an innovative curriculum } \\
\text { for assessment and UX professionals }\end{array}$ \\
\hline WoS-2 & $\begin{array}{l}\text { Choie, Hee-Soo; Kim, Sang- } \\
\text { Heon }\end{array}$ & 2017 & $\begin{array}{l}\text { A content service deployment plan for metaverse museum } \\
\text { exhibitions centering on the combination of beacons and } \\
\text { HMDs }\end{array}$ \\
\hline WoS-3 & Del Fiore, Giuseppe et al. & 2016 & $\begin{array}{l}\text { A location-aware architecture for an loT-based smart } \\
\text { museum }\end{array}$ \\
\hline
\end{tabular}




\begin{tabular}{|c|c|c|c|}
\hline Fonte & Autor & Ano & Título \\
\hline WoS-4 & Pallud, Jessie; Straub, Detmar & 2014 & $\begin{array}{l}\text { Effective website design for experience-influenced } \\
\text { environments: The case of high culture museums }\end{array}$ \\
\hline WoS-5 & Latham, Kiersten & 2012 & $\begin{array}{l}\text { Museum object as document Using Buckland's information } \\
\text { concepts to understand museum experiences }\end{array}$ \\
\hline WoS-6 & $\begin{array}{l}\text { Pallud, Jessie; Monod, } \\
\text { Emmanuel }\end{array}$ & 2010 & $\begin{array}{l}\text { User experience of museum technologies: the } \\
\text { phenomenological scales }\end{array}$ \\
\hline ProQuest-1 & $\begin{array}{l}\text { Koutsabasis, Panayiotis; } \\
\text { Vosinakis, Spyros. }\end{array}$ & 2018 & $\begin{array}{l}\text { Kinesthetic interactions in museums: conveying cultural } \\
\text { heritage by making use of ancient tools and (re-) } \\
\text { constructing artworks }\end{array}$ \\
\hline ProQuest-2 & $\begin{array}{l}\text { Fanini, Bruno; Pagano, } \\
\text { Alfonsina; Ferdani, Daniele. }\end{array}$ & 2018 & $\begin{array}{l}\text { A Novel Immersive VR Game Model for Recontextualization } \\
\text { in Virtual Environments: The } \mu \text { VRModel }\end{array}$ \\
\hline ProQuest-3 & $\begin{array}{l}\text { Roussou, Maria; Katifori, } \\
\text { Akrivi. }\end{array}$ & 2018 & $\begin{array}{l}\text { Flow, Staging, Wayfinding, Personalization: Evaluating User } \\
\text { Experience with Mobile Museum Narratives }\end{array}$ \\
\hline ProQuest-4 & Vu, Huy Quan et al. & 2018 & $\begin{array}{l}\text { Evaluating museum visitor experiences based on user- } \\
\text { generated travel photos }\end{array}$ \\
\hline ProQuest-5 & $\begin{array}{l}\text { Liu, Shunli; Idris, Muhammad } \\
\text { Zaffwan. }\end{array}$ & 2018 & $\begin{array}{l}\text { Constructing a framework of user experience for museum } \\
\text { based on gamification and service design }\end{array}$ \\
\hline ProQuest-6 & $\begin{array}{l}\text { Martín-Sabarís, Rosa-María; } \\
\text { Brossy-Scaringi, Gerardo. }\end{array}$ & 2017 & $\begin{array}{l}\text { Augmented Reality for Learning in People with Down } \\
\text { Syndrome: an exploratory study }\end{array}$ \\
\hline ProQuest-7 & Aluri, Ajay & 2017 & $\begin{array}{l}\text { Mobile augmented reality (MAR) game as a travel guide: } \\
\text { insights from Pokémon GO }\end{array}$ \\
\hline ProQuest-8 & Rosales, Ricardo et al. & 2017 & $\begin{array}{l}\text { Modelling the Interruption on } \mathrm{HCl} \text { Using BDI Agents with the } \\
\text { Fuzzy Perceptions Approach: An Interactive Museum Case } \\
\text { Study in Mexico }\end{array}$ \\
\hline Total: 14 & & & \\
\hline
\end{tabular}

Fonte: Elaborado pelos autres 


\section{O ENFOQUE INFORMACIONAL}

\subsection{Enquadramento da Ciência da Informação}

0 desenvolvimento e a disseminação das redes comunicacionais, após a II Guerra Mundial, motivaram uma expansão sem precedentes do volume e da diversidade dos recursos informacionais existentes. Neste contexto, a partir dos anos 50 do século XX, assiste-se ao aparecimento de vários estudos sobre uma ciência emergente, a Ciência da Informação (BORKO, 1968; BROOKES, 1980; FARRADANE, 1980; GOFFMAN, 1970; HJØRLAND, 1998; SARACEVIC, 1996; SILVA; RIBEIR0, 2008), como reflexo do valor central que a informação passa a ocupar na sociedade, a ponto de alguns autores defenderem que vivemos numa sociedade da informação (CAPURRO; HJØRLAND, 2003, P. 343; CASTELLS, 2002).

No entanto, o crescente envolvimento da comunidade científica em torno da caracterização da Ciência da Informação (CI) não se traduziu necessariamente num entendimento claro desta área. Pelo contrário, parece não haver um conceito uniforme de $\mathrm{Cl}$, mas antes vários sentidos distintos (RAYWARD, 1996; ZINS, 2006). Na base de este "caos conceptual” (SCHRADER, 1983, p. 99) está 0 facto de este campo científico ser pautado por diferentes abordagens e tradições, conforme a ideia defendida há várias décadas por Shera e Cleveland (1979), que vão desde as tecnologias à gestão dos recursos informacionais e/ou da documentação, passando ainda pelos enfoques comunicacionais, mais recentemente abordados por Capurro e Hjørland (2003, p. 396).

A enorme confusão e disparidade de definições em torno da Cl também é observável no conceito de "informação". Muitos autores têm-Ihe atribuído múltiplos significados, pelo que é observável uma falta de consenso teórico (VAKKARI, 1997). Apesar de esta falta de consenso, é frequente o conceito de informação (I) aparecer associado aos conceitos de dado (D) e conhecimento (C) e, por vezes, ao de sabedoria (ACKOFF, 1989; ROWLEY, 2007; SCHUMAKER, 2013). Porém, como se trata de um conceito muito elusivo, uma vez que diz mais respeito à intuição e interpretação humanas do que aos sistemas (JASHAPARA, 2004), não será considerado nas investigações decorrentes deste trabalho. Adotamos, portanto, um posicionamento, que entende que o conceito de informação não deve ser visto de forma isolada, mas antes em relação aos conceitos de dado, mensagem e conhecimento (SILVA; GOMES, 2015, P. 154; BUCKLAND, CIT. POR ZINS, 2006, P. 337). 
Os dados podem ser usados para criar informação, e a informação para gerar conhecimento. Apesar de não reunir consenso, de uma forma geral e simplificada, podemos entender os dados como elementos brutos sem significado, contexto ou estrutura, ao passo que a informação é o resultado de dados processados com uma finalidade, que os dota de significado (ROWLEY, 2007, p. 170-171). Por sua vez, o conhecimento consiste em informação estruturada e ordenada (MCHALE, 1981, p. 16), recebida e assimilada pela mente de um indivíduo (DAVENPORT; DONALD MARCHLAND, 2004, p. 190; ARAÚJ0, 2014a, p. 63).

Por conseguinte, o conhecimento identifica-se com algo inatingível, dado-que existe na mente dos indivíduos (ZINS, 2007, p. 479; ALLEN, 1996), por contraste com a informação, que é tangível. Como o conhecimento, as crenças e as opiniões são pessoais, subjetivas e concetuais: "to communicate them, they have to be expressed, described or represented in some physical way, as a signal, text, or communication" (BUCKLAND, 1991, p. 351). 0 conceito de mensagem, enquanto conteúdo dotado de significado (ZINS, 2006, p. 447), surge assim como o passo necessário para que uma informação possa ser percecionada por um indivíduo e assimilada como conhecimento. Como tal, a informação social, enquanto objeto de estudo científico, é entendida como um "conjunto estruturado de representações mentais codificadas (símbolos codificantes) socialmente contextualizadas e passíveis de serem registadas num qualquer suporte material (papel, filme, banda magnética, disco compacto, etc.) e, portanto, comunicadas de forma assíncrona e multidrecionada" (SILVA; RIBEIRO, 2008, p. 37).

Por extensão, posicionamo-nos num entendimento da $\mathrm{Cl}$ enquanto uma ciência de eminência humana e social (ARAÚJ0 2014b, p. 15), embora formada a partir da Biblioteconomia e da Arquivística, enriquecida por contributos interdisciplinares a respeito do estudo da informação, tais como a Psicologia, a História e a Comunicação (LE COADIC, 1996), que “investiga os problemas, temas e casos relacionados com o fenómeno info-comunicacional percetível e cognoscível através da confirmação ou não das propriedades inerentes à génese do fluxo, organização e comportamento informacionais (origem, coleta, organização, armazenamento, recuperação, interpretação, transmissão e utilização da informação)" (SILVA, 2006, p. 140-141). Num tal sentido, continua a ter pertinência aquela aceção há largos anos defendida por Cardoso (1996. p. 72), segundo a qual:

inexiste a informação independente de sua transmissão ou compartilhamento, que se faz pelo processo de comunicar (colocar em comum), bem como é impossível um ser humano (na acepção completa da expressão) desconectado da herança cultural comum ao grupo ao qual pertence. 


\subsection{Uma abordagem comunicacional da gestão da informação}

0 enfoque informacional já discutido acarreta igualmente uma necessidade de revisitação dos próprios procedimentos não só das instituições cujo objeto de trabalho é a informação social, nomeadamente os arquivos, as bibliotecas e os museus, mas também das organizações, de um modo geral, dado o valor ativo estratégico da informação (ECIA, 2005, p. 88). Como parte desta transição, tem sido tradicionalmente defendida a existência de dois paradigmas: um custodial e outro pós-custodial (SILVA; RIBEIRO, 2008). Todavia a Ciência da Informação, positivamente denominada de pós-custodial, que considera a informação e desvaloriza o documento, nunca abandonou a função de custódia, sem a qual não existe o processo infocomunicacional (SILVA, 2017, p. 10). Se quisermos considerar os dois paradigmas, que são coexistentes, teremos de relevar que a custódia documental integra a valorização da informação e do uso desta no longo prazo, sem o qual contexto não se entende, importando, em ambos os casos, reconhecer a informação enquanto valor estratégico ativo a gerir (SILVA, 2009).

Assim, na ótica aqui pretendida, a gestão da informação (Gl) consiste no conjunto de operações do fluxo infocomunicacional relacionadas com o 'objeto 'informação' num ecossistema organizacional. Essas operações referem-se às atividades de criação, organização e utilização, que implicam planeamento, execução, normalização e controlo (SILVA; CORUJO, 2019, p. 154). 0 processo infocomunicacional é, por sua vez, entendido como a transformação da informação contida num objeto para a sua assimilação por um utilizador enquanto conhecimento, através da comunicação (SILVA, 2006). Como é bom de ver, essa noção de informação como um "processo inextricável" relativamente ao conhecimento já antes havia sido analisada por Allen (1996), para quem o ato de conhecer (processo) implicaria, inevitavelmente, os atos de aprender e informar4.

0 ciclo de procedimentos indispensáveis para a GI constitui parte do sistema de informação. A noção essencial de sistema, conforme formulado por Ludwig von Bertalanffy, é a de "a complex of interacting elements" (VON BERTALANFFY, 1968, p. 55). Nesta aceção, a soma do todo é maior que a soma das partes, pois além do contributo de cada elemento a nível individual, a noção sistémica pressupõe também a teia de relações múltiplas e variadas estabelecidas entre esses elementos, agregadora de valor acrescentado e transformadora do próprio sistema, que sobre si mesmo age e

$4 \quad$ Segundo Allen (1996, p. 3): “[s]ei porque aprendi. Aprendi, porque fui informado. Da mesma forma, estou apto a informar alguém porque sei". 
interage, num processo dinâmico de autorregulação e de transformação (FREITAS; FERREIRA, 2007). Assim, um sistema de informação (SI) é:

\begin{abstract}
a totalidade formada pela interação dinâmica das partes, ou seja, possui uma estrutura duradoura com um fluxo de estados no tempo. Assim sendo, um Sistema de Informação é constituído pelos diferentes tipos de informação registada ou não externamente ao sujeito, não importa qual o suporte (material e tecnológico) de acordo com uma estrutura (entidade promotora/recetora) prolongada pela ação na linha do tempo (SILVA, 2006, p. 162).
\end{abstract}

Um sistema pressupõe a existência de uma "organisation of people, materials and machines that serve to facilitate the transfer of information from one person to another. Its function is social: to aid human communication» (VICKERY, 1973, p. 1). A componente tecnológica é uma das partes constituintes de um SI, mas não deve ser confundida com este. Como tal, não constitui o foco de um SI, mas tão só um meio de acesso à informação. Por este motivo, a tecnologia por si só não deve ser encarada como a solução para os problemas sociais, embora o seu uso seja atualmente um prérequisito para o desenvolvimento social e económico das nossas sociedades.

A finalidade dos serviços de informação é gerar produtos que sejam utilizados por indivíduos, quer internos - colaboradores - quer externos - a comunidade-alvo. Por isso, mais do que uma abordagem centrada na análise e no desenvolvimento dos meios tecnológicos de acesso à informação, deve promover-se o impacto social da gestão da informação na melhoria da qualidade de vida dos cidadãos (SILVA, 2019, p. 110-111), espelhando uma visão na qual o benefício das pessoas, enquanto destinatárias dos serviços de informação, é a referência central para o bom desempenho desses mesmos serviços.

\title{
3.3 A mediação informacional
}

Um conceito fundamental para a compreensão do fluxo infocomunicacional é 0 de mediação, central nas reflexões sobre a comunicação, sobretudo devido à expansão e à preponderância social dos mass media, nomeadamente da imprensa diária de larga tiragem, da televisão, da rádio e até dos próprios streams. Em suma, a mediação atua como "o elo entre o enunciador e o destinatário pelo qual se fundam e garantem a coerência e a continuidade institucionais da comunicação" (SILVA, 2009, p. 70).

A nível dos museus, entendemos a mediação como o processo de comunicação, que se dá entre um objeto em exposição e o olhar atento do visitante, que recebe essa informação e a assimila potencialmente como conhecimento. Consiste em "proposer aux visiteurs (idéalement à tous les visiteurs) de vivre une 
rencontre authentique avec les objets conservés au musée, leur permettre d'y donner du sens et d'en nourrir leur rapport au monde » (FAUCHE, 2002, p.4). Deste modo, os museus devem afirmar-se como lugares essencialmente comunicativos ao seu público, e não apenas armazéns cumulativos de artefactos pois "não existe comunicação sem cultura, nem cultura sem comunicação" (MARTíN-BARBER0, 1999, p. 67). Assim, o estudo da comunicação, enquanto processo, não pode ser fragmentado. Todos os seus elementos têm de ser estudados em conjunto, o emissor, a mensagem, 0 canal e o recetor. Todos eles interagem numa relação de interdependência, exigindo uma abordagem sistémica ao processo infocomunicacional (SILVA, 2009, p. 74).

\subsection{0 processo de comunicação}

Ao abordar a questão dos sistemas de comunicação, é incontornável a referência à teoria matemática da comunicação, de Shannon, apresentada em 1948, dada a sua vasta influência nas áreas relacionadas com a informação e a sua transmissão, ao longo da segunda metade do século XX. Para Shannon, o problema fundamental da comunicação era "that of reproducing at one point either exactly or approximately a message selected at another point. Frequently the messages have meaning; that is they refer to or are correlated according to some system with certain physical or conceptual entities" (SHANNON, 1948). Por isso, propõe um modelo de comunicação com 0 intuito de representar e reduzir o ruído existente na transmissão de um sinal. No seu artigo, Shannon refere-se ao uso comum da informação nas suas dimensões prática e semântica, ao mesmo tempo que redefine o conceito sob uma perspetiva da engenharia (CAPURR0; HJØRLAND, 2003, p. 343).

Shannon aponta o envolvimento de seis elementos: uma fonte de informação (information source), um transmissor (transmitter), uma mensagem (message), um canal (channel), um recetor (receiver), uma fonte de ruído e distorção (noise source) e um destinatário (destination), sendo que o transmissor codifica a mensagem e o recetor a descodifica (Shannon, 1948) para a entregar ao destinatário. É importante estabelecer uma ressalva de que esta teoria é uma teoria de sinal, não de transmissão da informação. Como tal, "this theory is not concerned with the communication of a meaningful message, but rather with the reproduction of a selection process. Shannon correlates information — that is, the number of possible choices in order to create a message — and uncertainty" (CAPURR0; HJØRLAND, 2003, p. 360). A informação figura, assim, como parceira da incerteza, numa 
associação que Weaver apelida de "bizarre e disappointing", porque não lida com o significado nem com a mensagem como um todo, mas tão-só como a ocorrência estatística de um conjunto de mensagens (SHANNON; WEAVER, 1963, p. 27).

Por estas razões, entende-se que esta teoria, embora faça porventura sentido a sua aplicação nas ciências computacionais e nas tecnologias eletrónicas aplicadas à informação, não é adequada para representar na sua totalidade o processo comunicacional em $\mathrm{Cl}$, "because it fails to accommodate the cultural realities of knowing and communicating, the phenomenological complexity of perception and understanding, or the interaction of the social and the personal" (BUCKLAND, 2012, p. 5). Mais do que uma mera transmissão de uma mensagem, a Cl preocupa-se com a aprendizagem e o conhecimento, assegurando as condições para que o processo infocomunicacional ocorra. Num museu, isso implica fornecer o contexto que reveste a produção do objeto informacional em exposição. De igual modo, a Cl deve ser vista sob um enfoque cultural (BUCKLAND, 2012), na medida em que os objetos informacionais são fruto de um contexto social, económico e cultural. 0 contexto implica a cultura e vice-versa. As pessoas produzem os meios de que necessitam para a sobrevivência tendo em conta o momento particular no qual experienciam as suas vivências (MAGNANI, 1986). Logicamente, as manifestações caraterísticas da cultura vinculam-se à identidade, na aceção de constructo coletivo. No tocante à relação cultura / informação, sendo esta (a informação) uma prática intersubjetiva, compartilhada pelo todo social, é também um elemento "instituinte da cultura, ao revelar novas alternativas possíveis para a ação, que se cristalizam em práticas a serem consideradas, reinterpretadas, reformuladas ad infinitum, dando ocasião ao aparecimento e consolidação de outras manifestações culturais" (CARDOSO, 1996, p. 72). Assim, por exemplo, uma pintura renascentista incorpora na sua representação os estilos, as correntes artísticas e os conceitos religiosos coevos, da mesma maneira que um fóssil de um réptil com dentes surge no decorrer de um período zoológico com as suas especificidades, que são necessários compreender para enquadrar esse artefacto. Neste último caso, a palavra 'social' tem uma aceção mais abrangente. No âmbito da $\mathrm{Cl}$, a informação deve portanto ser encarada como um fenómeno e um processo (ALLEN, 1996; RASCÃO, 2006; SILVA, 2006), no sentido em que se trata de um fenómeno gerado na mente humana que, ao ser exteriorizado, é submetido a um processo infocomunicacional que o molda (SARACEVIC, 1996; FREITAS, FERREIRA, 2007), e constitui ele próprio valor informativo, enquanto reflexo das condicionantes sociais, culturais ou naturais que revestem a materialização da informação no suporte. 


\section{O MUSEU COMO UM SISTEMA DE INFORMAÇÃO}

\subsection{Breve caracterização do sistema}

Um museu é uma instituição de caráter permanente, com ou sem personalidade jurídica, dotada de uma estrutura organizacional que Ihe permite: a) garantir um destino unitário a um conjunto de bens culturais e valorizá-los através da investigação, incorporação, inventário, documentação, conservação, interpretação, exposição e divulgação, com objetivos científicos, educativos e lúdicos; b) facultar acesso regular ao público e fomentar a democratização da cultura, a promoção da pessoa e o desenvolvimento da sociedade (PORTUGAL, 2004).

Apesar de a lei se referir à gestão dos artefactos físicos, entende-se 0 museu como uma instituição cuja missão é gerir e divulgar a informação sob a sua alçada, através do cumprimento dos procedimentos acima mencionados. Por conseguinte, segundo uma interpretação europeia, a museologia afirma-se como uma disciplina inserida na epistemologia da Ciência da Informação. Alguns autores têm dado importância aos aspetos partilhados entre museus, bibliotecas e arquivos, suas disciplinas próximas (MARQUES, 2010, p. 27; SILVA, 2002), enquanto outros (BELLOTTO, cit. por SILVA, 2002, p. 578) têm apontado as suas diferenças. Esta posição não é inteiramente consensual no contexto brasileiro. Enquanto que autores como Ferrez e Bianchini (1987) assumem uma perspetiva que entende o museu como um sistema de informação, constituindo os acervos fontes de informação, colocando a Museologia sob a asa da Ciência da Informação, outros autores postulam a museologia como uma disciplina científica (BRANDÃ0, 1993; PINHEIR0, 2012) que se encontra institucionalizada por uma longa tradição (COSTA, 2017, p. 47), ainda que por vezes dispersa institucionalmente (ARAÚJ0, 2011, p. 120). Neste estudo, mais do que argumentar sobre a relação de eventual autonomia entre a Museologia e a Ciência da Informação, importa salientar na que literatura várias vozes se têm pronunciado sobre as relações interdisciplinares entre estas duas áreas, sobretudo ao longo das últimas duas décadas (PINHEIRO, 2007).

Neste estudo não é pertinente entrar na discussão entre a caracterização das três instituições culturais - arquivos, bibliotecas e museus - que Silva (2002, p. 580) considera levar a confusões concetuais e terminológicas que "resultam inevitavelmente da necessidade corporativa de distinguir atividades profissionais sem questionar o paradigma subjacente". 
Considera-se apenas importante salientar um aspeto singular dos museus: a posse de coleções de objetos bi/tridimensionais e exemplares únicos, reunidos pelo conteúdo ou pela função e produzidos pela atividade humana com fins artísticos, culturais e funcionais. A sua gestão evoca uma abordagem sistémica, na aceção considerada mais atrás, o que permite entender o museu como um sistema de informação (MARQUES, 2010). Muito embora este serviço possa constituir um sistema, não deve ser confundido com o próprio SI. A Figura 1 constitui, pois, um esquema lógico dos elementos grosso modo identificados como mais relevantes para a prestação desse serviço. Como input podem figurar informações das coleções, informação museológica ou informação de gestão que integradas no sistema de informação de um museu (KAVAKLI; BAKOGIANNI, 2003). Os artefactos também podem constituir um input, sendo manuseados por determinado agente (p.e., um curador) que os organiza, interpreta e dispõe sob forma de um output (p.e., uma exposição). A interação dos visitantes com esse output pretende gerar um determinado outcome ou resultado (p.e., aprendizagem), e é mediada pelo sistema tecnológico de informação do museu.

Figura 1 - Elementos essenciais do sistema de informação de um museu.

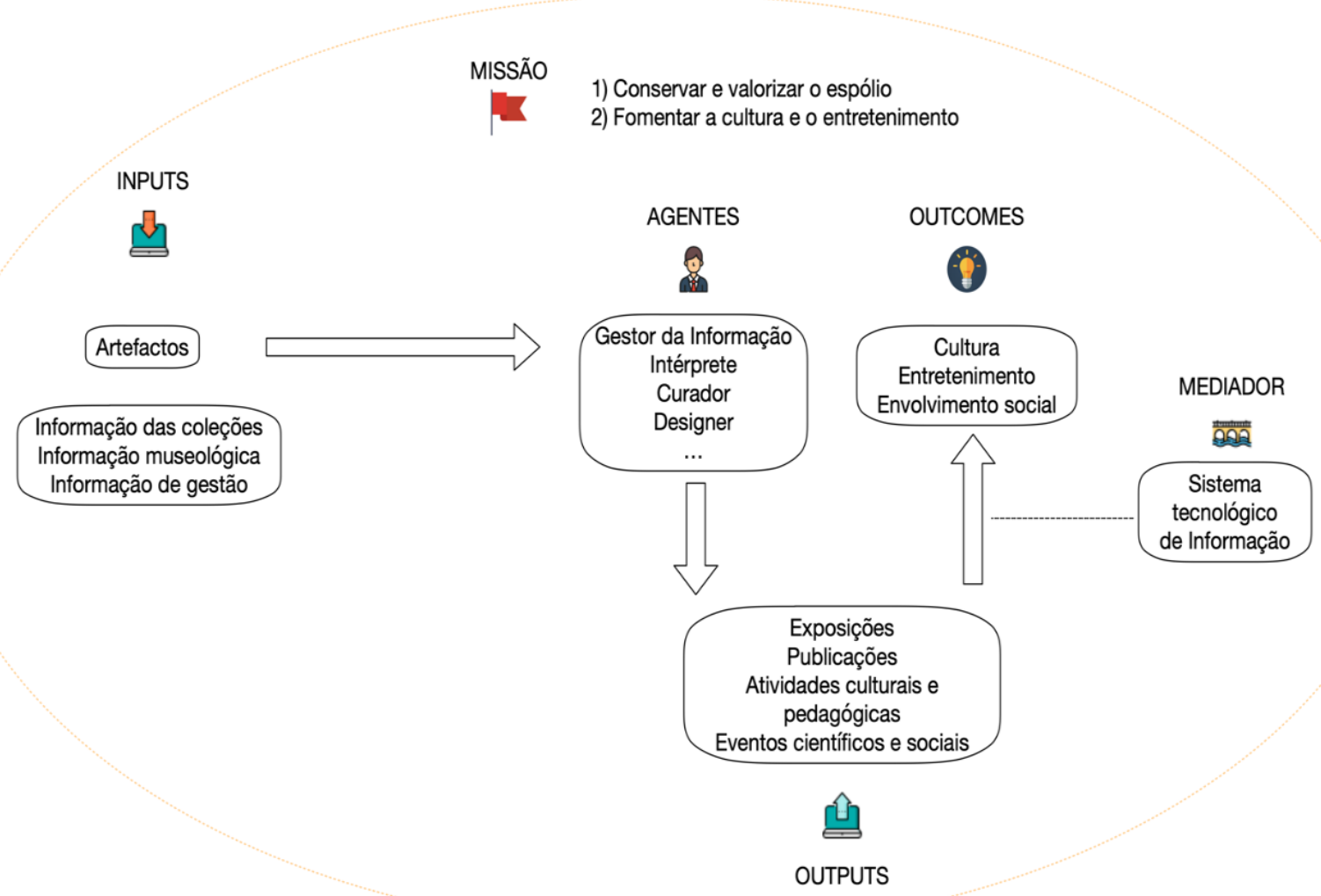

Fonte: Elaboração dos autores 
Assim, também os museus devem abandonar uma perspetiva de gestão custodial e patrimonialista das suas coleções, evoluindo da sua aceção estática de "collective memory bank of human achievement, through a collection of objects“ (WATEREN, 1999, p. 193), para se afirmarem como instituições cujo enfoque é o valor do serviço informacional que prestam à comunidade do território onde se encontram cultural e geograficamente inseridos.

\subsection{0 objeto científico dos museus}

Antes de considerarmos os visitantes do sistema museológico, importa fazer um esclarecimento quanto à noção do seu objeto científico. Uma vez que o foco deste trabalho é a dimensão comunicativa das exposições, a documentação gerida pelo museu não é aqui considerada para efeitos de objeto salvo se se encontrar em exposição. Assim, surge a dúvida se todos os objetos presentes num museu — tais como fósseis, utensílios de civilizações passadas, quadros, etc._- podem ser entendidos como documentos.

Certos autores consideram que os objetos dos museus são documentos porque contêm informação, formulando os museus como instituições documentais (BRIET, 1951, p. 7; 0TLET, 1934, p. 217-218). Na verdade, um documento pressupõe a informação registada num suporte com uma intenção comunicativa, pelo que um esqueleto ou um vaso, não tendo tido uma intencionalidade comunicativa a presidir à sua criação, teve quando da sua reunião e depósito no Museu. Um quadro ou uma fotografia, por sua vez, tem essa intencionalidade desde a sua criação, na medida em que teve um autor humano que materializou as suas ideias num suporte que permite comunicar essa informação a outros. Assim, defende-se a posição de Mensch (1990, p. 144) e adota-se 0 uso do termo 'artefactos' para referir 0 objeto dos museus. Embora alguns destes objetos não resultem da atividade humana, ou não tenham uma intenção comunicativa, eles podem ser entendidos enquanto portadores de informação, uma vez que os diferentes tipos de conhecimento (histórico, social, artísticos, geográfico, etc.) são suscitados pelo tipo de informação do objeto (MAROEVIC, 2006, pp. 334-335).

\subsection{Modelos de comunicação em museus}

Ao colocarmos o enfoque no valor informacional, estamos a afirmar que os museus não existem por causa dos objetos que contêm, mas sim devido aos conceitos ou ideias que esses objetos ajudam a veicular (SOLA, 1986, p. 15). 0 mais importante é a informação de que se revestem, sobretudo 0 
contexto deles decorrente, que difere do presente e, por isso, importa entender. Stransky (1974, p. 32) condensa esta noção ao atribuir aos objetos museológicos a característica de musealium, isto é, a de serem objetos separados da sua realidade e transferidos para um museu, onde encontram nova realidade, de forma a documentar a realidade da qual são originários. Schreiner desenvolve esta noção de objeto musealizado, atribuindo-Ihe as seguintes características: são testemunho de algo; são descontextualizados com fins de conservação; são selecionados ou adquiridos para uma determinada coleção e são preservados e descodificados; são utilizados com finalidades sociais, intelectuais, culturais, nomeadamente através da sua exposição e outras formas de comunicação (SCHREINER, 1984, p. 24-28). A figura 2, baseada no modelo de Shannon, pretende representar este processo.

Figura 2 - Modelo de codificação/descodificação da informação em museus

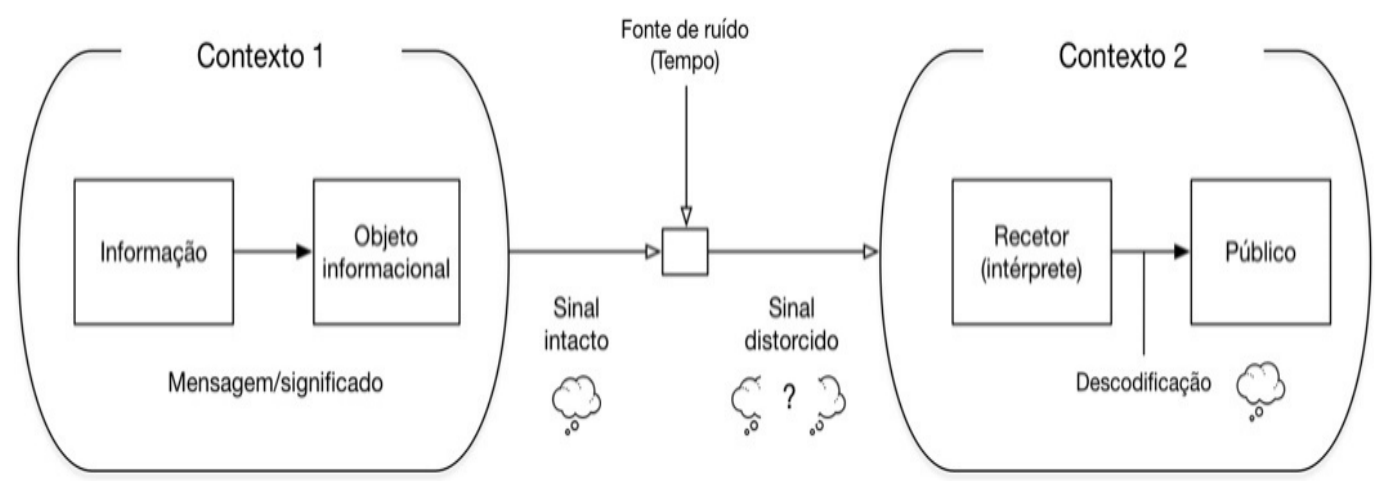

Fonte: Elaboração própria.

Uma determinada informação é materializada e registada num objeto informacional, que pode ser criado por um autor (uma joia, faca, moeda) ou gerado pela Natureza (rocha, fóssil, cristal). Em ambos os casos, o artefacto possui um contexto cultural ou natural original, indispensável para a compreensão da mensagem e do significado que ele veicula. No entanto, a passagem do tempo distorce esse significado inicial, uma vez que induz a alteração do contexto. Portanto, quando 0 intérprete, no presente - que é um futuro em relação ao momento de criação — interage com 0 artefacto, ele habita num contexto diferente, dentro do qual aquele artefacto lhe é estranho. Ainda assim, ele encara o sinal distorcido do artefacto (quer fisicamente, por estar partido, incompleto ou descolorido, ou simplesmente por ser o produto de uma época distinta) e gera uma interpretação do seu significado, de modo a recriar uma hipótese do sentido inicial. Diz-se interpretação, e não conclusão, porque este nunca pode compreender na sua totalidade o contexto original, dado que nunca habitou nele. Por isso, como toda a nossa perceção do passado é uma construção que resulta 
da interpretação dos dados disponíveis, que podem ser mais ou menos fidedignos, o intérprete nunca pode afirmar com certeza que compreende o contexto original e que, portanto, o sentido do objeto é absoluto. Formula meramente uma hipótese interpretativa. Finalmente, fornece esse sentido reconstruído e 'intacto' ao público, a quem é dada a possibilidade de consumir essa informação e de a transformar em conhecimento.

Neste aspeto, assume particular importância o processo de mediação, enquanto estratégia de comunicação, que se estabelece entre os objetos informacionais e os utilizadores da informação no museu, permitindo a vivência e a partilha de experiências entre os visitantes. Assim, o museu afirma-se como promotor de aprendizagens, facilitador da apropriação de contextos e, sobretudo, um lugar de transformação (DESVALÉES; MAIRESSE, 2013, p. 53). 0 mais comum é o mediador ser apresentado como sendo um agente humano, como um arquivista, um bibliotecário, um museólogo ou um designer de conteúdos (SILVA, 2009, p. 90). No entanto, no âmbito de um museu, faz igualmente mais sentido entender o sistema tecnológico de informação, o museu virtual, como o agente de mediação entre os objetos informacionais e os visitantes.

Embora todas as estruturas tecnológicas sejam obra humana e, por conseguinte, uma pessoa esteja sempre na conceção do processo de mediação, no âmbito de um espaço museológico (como uma exposição) o canal de comunicação é ocupado por uma tecnologia, que pode ir de uma simples etiqueta a uma apresentação audiovisual sobre o objeto. Em ambos os casos, 0 STI é o responsável por operar a comunicação entre o objeto e o visitante, através do qual este assimila o sentido reconstruído do artefacto e enriquece potencialmente 0 seu conhecimento. Para tal, Thaller identifica cinco requisitos dos STI, cuja finalidade é a representação de fontes de informação:

(1) represents the artifacts as free from any interpretation as possible in the technical system, (2) embeds them, however, in a network of interpretations of what they imply, (3) provides tools which help to remove contradictions between such interpretations, (4) accepts, however, that such contradictions may prove to resist resolution, (5) as well as that all interpretations always represent tendencies, no certainties" (Thaller, 2018).

Conforme visto anteriormente, salienta-se o carácter especulativo das interpretações e a necessidade de contextualizar as informações veiculadas pelos objetos. 
Figura 3 - Esquema simplificado dos fluxos informacionais de um museu

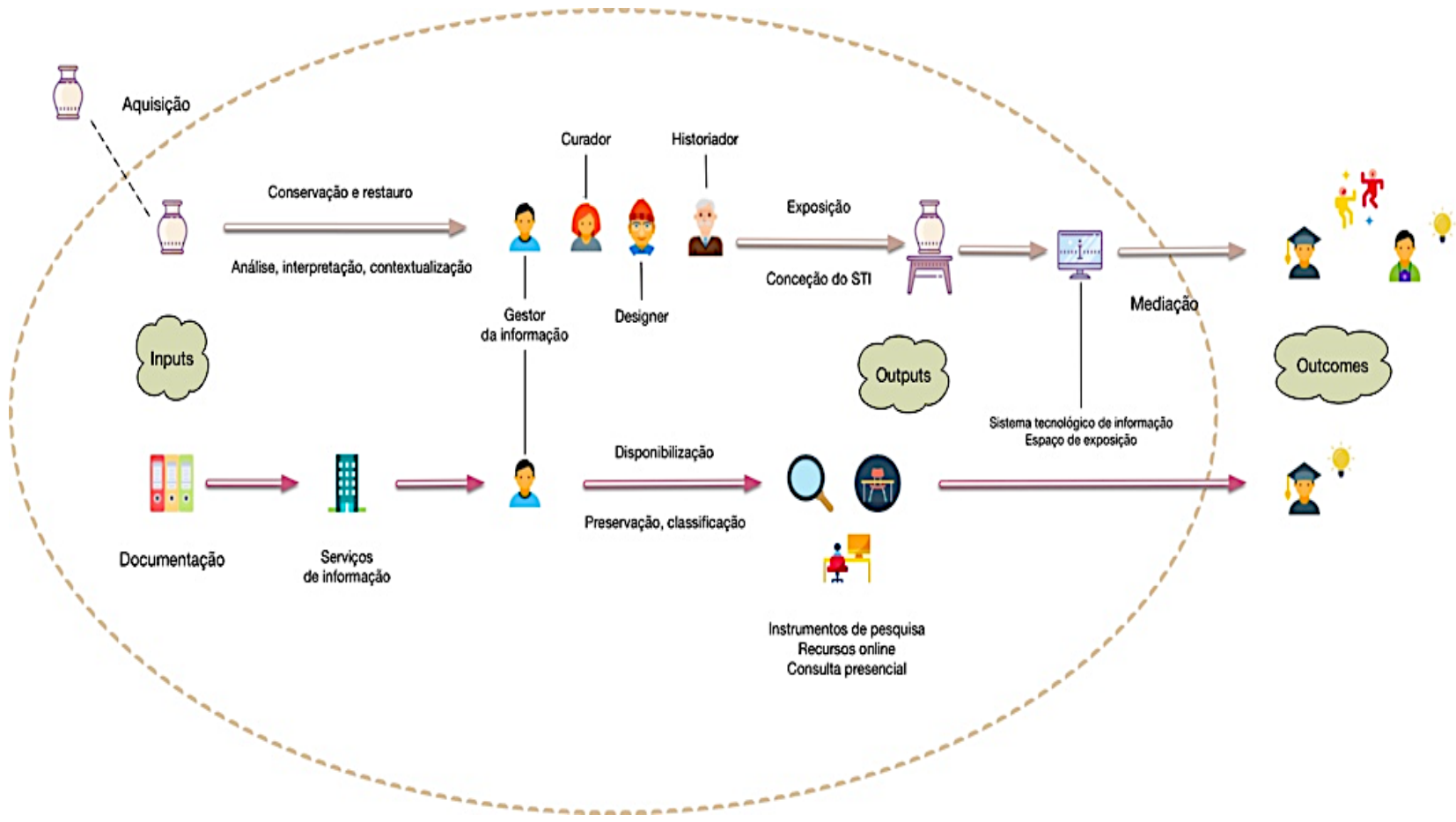

Fonte: Elaboração própria.

0 papel dos STI no processo comunicativo da informação num museu é apresentado na Figura 3. Tratando-se de um esquema simplificado, admite-se que possa estar incompleto. Todavia, apenas procura representar os principais intervenientes e procedimentos decorrentes dos fluxos informacionais desde a aquisição de um artefacto até à sua comunicação através da sua exposição, bem como a sua missão geral. De uma forma geral e linear, o esquema pretende orientar a seguinte leitura: um artefacto (input) é adquirido pelo museu e incorporado na sua coleção; é alvo de ações de conservação, sendo depois preservado em condições ótimas; a par desta tarefa, destacam-se: 0 gestor da informação, que gere a informação associada ao artefacto (descrição e indexação); 0 designer de software, que concebe e implementa a tecnologia de interação com 0 artefacto (p.e. vídeo); 0 curador, que concebe a exposição; e 0 historiador, que descodifica o sentido distorcido e fornece uma interpretação do significado. 0 artefacto é então colocado em exposição (output), acompanhado pelo STI que o contextualiza e descreve, atuando como o canal de comunicação, que permite aos visitantes fomentar o conhecimento (outcome). Uma vez que a produção destes outcomes é uma das missões fundamentais do museu, reforça-se a necessidade de ser este 0 enfoque da avaliação dos sistemas, e não a disponibilização acrítica do serviço por si só. 


\section{USER EXPERIENCE}

\subsection{Definição e enquadramento}

0 termo user experience (UX), ou experiência dos utilizadores, surgiu pela primeira vez em 1995 como forma de descrever os avanços no desenvolvimento de interfaces e aplicações para utilizadores (NORMAN; MILLER; HENDERSON, 1995). A investigação e a realização de testes em UX permite analisar as relações complexas, que se estabelecem entre os utilizadores, as características do sistema e o contexto de interação, de forma a desenvolver produtos e serviços, que não só evitem um uso difícil, mas também que constituam uma experiência positiva (FELMING-MAY et al., 2018, p. 1).

A UX surge assim como uma forma de ir ao encontro das expetativas dos utilizadores, e até mesmo de as superar, respondendo às suas necessidades. Todavia, é importante realçar que as expetativas são algo em permanente construção, dependendo diretamente da qualidade de cada entidade e da imagem que projeta, incluindo as formas de comunicação (LEITÃO, 2018, p. 70), bem como de eventuais experiências de interação anteriores entre o cliente e a entidade. Logo, após uma primeira visita de sucesso, a entidade tem de continuar a mostrar altos níveis de desempenho com base nas necessidades do seu público (MILLER, 2000).

A perceção e a avaliação da UX têm-se afirmado como uma área de investigação na Cl, dando azo ao desenvolvimento de vários estudos sobre a interação entre pessoas e a tecnologia (PALLUD; MONOD, 2010, p. 563). No entanto, os profissionais da informação ainda possuem escassas normas para avaliar a experiência dos utilizadores (INSTITUTE OF MUSEUM AND LIBRARY SERVICES, 2006; TOST; ECONOMOU, 2007; SILVA, 2019), notando-se também a falta de preparação académica sobre esta matéria (APPLEGATE, 2016; NITECKI, WIGGINS, TURNER, 2015). Ainda assim, as investigações existentes têm apontado para o carácter variado e multidimensional da UX, que exige uma abordagem multidimensional (ISOMAKI, 2009; MCCARTHY; WRIGHT, 2004) ou, por outras palavras, sistémica. Pauta-se por uma matriz essencialmente pessoal e subjetiva, enquanto "a consequence of the user's prior experiences, attitudes, skills, habits and personality” (ISO 9241-210, p. 2000). De facto, é com base no conhecimento prévio que os utilizadores recebem a informação e a assimilam de acordo com 0 que, no seu entendimento, é pertinente, num processo de permanente construção e desconstrução do conhecimento (DAVENPORT; DONALD MARCHLAND, 2004, p. 190; ROWLEy, 2007, p. 173). Por este motivo, a investigação nesta área deve superar a perspetiva puramente focada nas tecnologias, que 
normalmente vigora no desenvolvimento dos sistemas de informação (HASSENZAHL; TRACTINSKY, 2006, p. 92), focando-se antes numa perspetiva mais humana de compreensão das emoções e dos afetos resultantes dessa experiência de contacto.

\subsection{A experiência dos visitantes nos museus}

Os museus são locais onde as pessoas procuram experiências e sentidos (CARR, 2001). Há um desejo inerente de interagir com o património de forma a conhecer mais sobre a história (PORIA, REICHEL, BIRAN, 2006) e sobre nós próprios (KIMMELMAN, 2001). Como tal, enhancing UX by providing cultural entertainment and education is the crucial target for museums (ICOM, 2007). No entanto, esta aprendizagem sobre o passado é uma experiência altamente pessoal para o visitante, pois depende das suas necessidades e do seu contexto de aprendizagem que, como visto anteriormente, varia em função do seu conhecimento prévio, consoante o qual filtra a informação.

Neste sentido, os museus - e, por extensão, as tecnologias por eles usadas com este fim - devem ser capazes de garantir uma experiência apropriada às necessidades dos seus visitantes, sejam elas de natureza funcional (educativas) ou hedónicas (de entretenimento) (PALLUD; MONOD, 2010, p. 574). Esta ideia evoca a de fato museológico de Waldisa Guarnieri segundo a qual existe uma relação profunda entre os indivíduos, enquanto sujeitos cognoscentes, e os objetos, enquanto parte de uma realidade que o indivíduo constrói (GUARNIERI, 1989, p. 7). A título de exemplo, a forma como se comunica a informação veiculada por um artefacto é distinta quando o público-alvo é um grupo de crianças ou um grupo de investigadores da área, o que leva a diferentes experiências. Apesar de estas diferenças, o mesmo STI deve ser suficientemente versátil para servir como mediador entre a informação e os visitantes. Por este motivo, Valachich et al. (2007) sugerem uma interessante imagem dos sistemas como um contínuo, com dois polos em que cada um é ocupado pelas necessidades hedónicas e utilitárias. De uma forma geral, foi demonstrado que as tecnologias que veiculam contexto, empatia, interatividade e sensações são as que contribuem para experiências mais positivas dos visitantes (PALLUD; MONOD, 2010; TOST; ECONOMOU, 2007). Assim, respondendo à primeira questão de investigação, identificamos a proporção de uma experiência positiva aos visitantes como uma das finalidades centrais de um museu.

Assim, as exposições, tal como as demais experiências que têm lugar nos museus, serão, ao mesmo tempo, informacionais, comunicacionais e interativas. No entanto, como a informação possui 
um caráter contextual (MAHLER, 1996), para que seja assimilada pelos visitantes e enriqueça os seus conhecimentos, é necessário contextualizá-la por meio da contextualização dos artefactos. A mediação é, portanto, entendida como o processo que compreende a transmissão da informação/significado de um objeto informacional - significado esse assente na compreensão do contexto que presidiu à sua criação - e a assimilação dessa informação/significado por um visitante pertencente a um contexto diferente - e, por conseguinte, para o qual o artefacto, por si só, é um objeto estranho e incompreensível — de modo a enriquecer a sua experiência e aprendizagem. Deste modo, a mediação consiste no processo de facilitação da aprendizagem, baseada na experiência do utilizador.

Mas a mediação também depende grosso modo do STI, na medida em que este normalmente fornece o contexto e o sentido dos artefactos, quer através de etiquetas, quer através de uma componente interativa de painéis informativos adicionais. No entanto, a mediação, tal como aqui formulada, vai mais além. Umberto Eco (2005), numa conferência em que aborda o papel dos museus no terceiro milénio, lançou uma proposta audaz: de forma a enriquecer o conhecimento do contacto entre a cultura eurocêntrica e as restantes culturas, um museu deveria ser disposto na forma de um labirinto, em que cada caminho fosse consignado a uma história própria. Neste museu, por exemplo, a história da Europa seria paralela à história da América até 1492, momento a partir do qual ambos os caminhos se fundiriam num só, e se prolongariam em conjunto. Neste exemplo, 0 visitante teria a possibilidade de construir a sua própria história ao mesmo tempo que a compara com outras histórias paralelas, naquilo que seria uma experiência enriquecida e exacerbada por uma componente visual e espacial, que tende a despertar a sua curiosidade, interesse e aprendizagem. A sugestão de Eco ilustra notavelmente o modo como o conceito de 'experiência de utilizadores' não reside apenas no domínio das aplicações tecnológicas, mas como pode também ser expandido para referir a experiência do utilizador como um todo, respondendo assim à segunda questão de investigação.

Como segundo exemplo, pensamos na pintura Bonaparte franchissant le Grand-Saint-Bernard, da autoria do pintor francês Jacques-Louis David. Em todas as suas cinco versões, Napoleão surge triunfante atravessando os Alpes, montado num cavalo poderoso e imparável. Um visitante inocente, vendo esta pintura, fica de imediato com uma ideia majestosa deste imperador, tal como era intenção do autor e do próprio retratado. Contudo, é preciso não esquecer que esta pintura foi encomendada pelo próprio Napoleão no âmbito de uma estratégia de grandificação da qual, de um modo geral, os monarcas se servem. Muito provavelmente, Napoleão até atravessou a cordilheira montanhosa encolhido no seu casaco, enregelado e diminuído, num cenário real muito distinto do aspeto triunfante 
dado pelo autor. Aliás, ao encomendar o quadro, o próprio Napoleão afirma que "é o carácter que determina o que deve ser pintado [...] Ninguém sabe se os retratos dos grandes homens são parecidos com eles, basta que o seu génio neles habite"5.

Como tal, é difícil dissociar a figura representada do contexto de produção da obra ou, por outras palavras, é difícil perceber o significado de um objeto informacional sem compreender 0 contexto em que ele se insere. Este ato interpretativo, que constitui a essência da investigação em história (THALLER, 2018), é a pedra basilar da mediação no espaço museológico. 0 sucesso deste ato comunicativo, dominado pela participação do STI, mas a ele não reduzido, é a chave para promover uma experiência rica do visitante, quer de natureza lúdica quer educacional, procurando para isso adaptar-se às suas necessidades, em vez de disponibilizar os seus acervos com uma autoridade unilateral. Em vez da atitude educativa dirigista 'eu ensino-te', oferece-se a proposta de mediação 'eu faço-te aprender'. Uma tal viragem baseia-se no reconhecimento de que os indivíduos constroem significados a partir de experiências que não podem reduzir-se a uma lógica consumista de informação. Como inibidores desta lógica, relevam as atitudes e os meios que levam os indivíduos ao acesso aos "atalhos" que lhes permitam interpretar a(s) realidade(s) e construir os seus próprios significados (PORTO, 1998). Por este motivo, em resposta à terceira questão de investigação, entende-se que o conceito de 'mediação' se deve alargar, deixando de ser percecionado unicamente como um ato entre humanos, para incluir uma lógica de comunicação que privilegie o binómio artefacto-observador.

\section{CONSIDERAÇÕES FINAIS}

Este estudo foi moldado pelo objetivo de averiguar preliminarmente as possibilidades de integração teórica dos conceitos de experiência do utilizador com as dimensões sistémicas de experiência pessoais em museus. Analisou-se como a valorização da experiência pessoal dos indivíduos, durante a visita, deve ser um critério determinante para fundamentar a atividade cultural dos museus e para potenciar a aprendizagem. Consideram-se respondidas as questões de investigação propostas pois a) a experiência tem de ser encarada de forma sistémica, não se resumindo unicamente à conceção e design de aplicações informáticas, b) mas compreendendo todo o processo de contacto que um visitante tem com a informação veiculada pelo objeto que, além de incluir naturalmente uma

$\overline{5 \text { Ressemblant? }}$ Ce n'est pas l'exactitude des traits, un petit pois sur le nez qui font la ressemblance. C'est le caractère de la physionomie ce qui l'anime qu'il faut peindre. [...] Personne ne s'informe si les portraits des grands hommes sont ressemblants, il suffit que leur génie y vive. 
componente de mediação pelo sistema tecnológico de informação, c) pode também passar por uma experiência estética do espaço e da representação da obra.

Consequentemente, partindo de um conceito de objeto informacional e da teoria da comunicação, a mediação no espaço interativo do museu é aqui entendida como o processo infocomunicacional entre um artefacto, enquanto um objeto informacional, e um visitante que atua como recetor dessa informação, que pode transformar em conhecimento. 0 sistema tecnológico de informação é o canal de comunicação segundo o qual um emissor (o artefacto) veicula um significado (informação) a um recetor (o visitante). Como tal, atua como mediador entre a emissão de um significado distorcido de um objeto, fruto do seu contexto estranho ao presente, e a receção do significado reconstruído, "ressignificado", na medida em que é interpretado e contextualizado na realidade do visitante.

A limitação principal do estudo prende-se com a reduzida dimensão da amostra de artigos científicos, que pode condicionar a representatividade da revisão de literatura. Novos estudos com um corpus documental mais alargado e diversificado em tipologia poderiam aprofundar a discussão do conceito alargado de mediação, bem como explorar novas modalidades mais criativas de enriquecimento das experiências dos utilizadores em museu.

\section{AGRADECIMENTOS}

Este estudo foi financiado em parte pela Fundação para a Ciência e Tecnologia através da bolsa de doutoramento SFRH/BD/131004/2017.

\section{REFERÊNCIAS}

ACKOFF, Russel. From data to wisdom. Journal of Applied Systems Analysis, v. 16, n. 1, p. 3-9, 1989.

AGARWAL, Ritu; KARAHANNA, Elena. Time flies when you're having fun: cognitive absorption and beliefs about information technology usage. MIS Quaterly, v. 24, n. 4, p. 665-694, 2000.

ALLEN, Bryce. Information tasks: toward a user-centered approach to information systems. San Diego: Academic Press, 1996. Cap. 1: Introduction, p. 1-23.

APPLEGATE, Rachel. Educating Assessors: preparing librarians with Micro and Macro skills. Evidence Based Library and Information Practice, v. 11, n. 2, p. 74-86, 2016. 
ARAÚJO, Carlos Alberto Ávila. Ciência da Informação, Biblioteconomia, Arquivologia e Museologia: relações teóricas e institucionais. Encontros Bibli: revista eletrônica de biblioteconomia e ciência da informação, v. 16, n. 31, p. 110-130, 2011.

ARAÚJO, Carlos Alberto Ávila. Fundamentos Da Ciência Da Informação. Perspectivas em Gestão \& Conhecimento, v. 4, n. 1, p. 57-79, 2014a.

ARAÚJO, Carlos Alberto Ávila. 0 que é Ciência da Informação? Informação \& Informação, v. 19, n. 1, p. 1-30, 2014b.

BLYTHE, M. et al. Funology: from usability to enjoyment. Dordrecht: Kluwer Academic Publishers, 2003.

BORK0, Harold. Information Science: what is it? American Documentation, v. 19, n. 1, p. 3-5, 1968.

BOWEN, Glenn A. Document Analysis as a Qualitative Research Method. Qualitative Research Journal, v. 9, n. 2, p. 27-40, 2009.

BRANDÃO, José Manuel. International Summer School of Museology (ICOM/UNESCO). Cadernos De Museologia, v. 1, p. 72-78, 1993.

BRIET, Suzanne. Qu'est-ce que la documentation? Paris: ÉDIT, 1951.

BROOKES, Bertram. The foundations of information science. Part I. Philosophical aspects. Journal of Information Science, v. 2, p. 125-133, 1980.

BRYMAN, A. Social research methods. [s.I.] Oxford University Press, 2016.

BUCKLAND, Michael. Information as thing. Journal of the American Society for Information Science, v. 42, n. 5, p. 351-360, 1991.

BUCKLAND, Michael. What Kind of Science Can Information Science Be? Journal of the American Society for Information Science and Technology, v. 1, n. 1, p. 1-7, 2012.

CAPURRO, Rafael; HJØRLAND, Birger. The Concept of Information. Annual Review of Information Science and Technology, v. 37, n. chapter 8, p. 343-411, 2003.

CARDOSO, A. M. P. Pós-modernidade e informação: conceitos complementares? Perspectivas em Ciência da Informação, v. 1, n. 1, p. 63-79, 1996.

CARR, D. A museum is an open work. International Journal of Heritage Studies, v. 7, n. 2, p. 173183, 2001.

CASTELLS, Manuel. A era da informação: economia, sociedade e cultura. Lisboa: Fundação Calouste Gulbenkian, 2002.

COSTA, Luciana. Museologia no Brasil, século XXI: atores, instituições, produção científica e estratégias. [s.I.] Universidade de Évora, 2017. 
DAVENPORT, Thomas; DONALD Marchland (Ed.). Dominando a gestão da informação. 5 ed ed. Porto Alegre: Bookman, 2004.

DESVALLEES, Andre; MAIRESSE, Françoi (Ed.). Conceitos-chave de Museologia. São Paulo: Comitê Brasileiro do Conselho Internacional de Museus, 2013.

ECO, UMBERTO. El museo en el tercer milénio. Revista de Occidente, v. 290-291, n. jul./ago., p. 33-53, 2005.

EUROPEAN COUNCIL OF INFORMATION ASSOCIATIONS [= ECIA]. Euro-Referencial I-D. Lisboa: INCITE, 2005.

FARRADANE, J. Knowledge, information, and information science. Journal of Information Science, v. 2, n. 2, p. 75-80, 1980.

FAUCHE, Anne. La médiation-présence au musée d'Histoire des sciences de Genève: enjeux, objectifs, pratiques, réflexions. La Lettre de I’OCIM, v. 83, p. 3-9, 2002.

FELMING-MAY, Rachel et al. Experience assessment: designing an innovative curriculum for assessment and UX professionals. Performance Measurement and Metrics, v. 19, n. 1, p. 30-39, 2018.

FERREZ, Helena; BIANCHINI, Maria. Thesaurus para acervos museológicos. Rio de Janeiro: Fundação Nacional Pró-Memória, 1987.

FREITAS, Maria Cristina Vieira de; FERREIRA, Daniela Assis Alves. Aspectos e reflexões conceituais sobre informação, sistemas e teoria de sistemas. VII Encontro Nacional de Ensino e Pesquisa da Informação. Salvador: UFBA, 2007.

GIL, Antonio Carlos. Métodos e técnicas de pesquisa social. São Paulo: Atlas, 2008.

GOFFMAN, William. Information science: discipline or disappearance. Aslib Proceedings, v. 22, n. 12, p. 589-596, 1970.

GUARNIERI, Waldisa. Museu, Museologia, museólogos e formação. Revista de Museologia, v. 1, p. 7-11, 1989.

HASSENZAHL, H.; TRACTINSKY, N. User experience - a research agenda. Behavior \& Information Technology, v. 25, n. 2, p. 91-97, 2006.

HASSENZAHL, Marc; ROTO, Virpi. Being and doing: a perspective on user experience and its measurement. Interfaces, v. 72, p. 10-12, 2007.

HJØRLAND, Birger. Theory and metatheory of information science: A new interpretation. Journal of Documentation, v. 54, n. 5, p. 606-621, 1998.

HOLBROOK, M. The millenial consumer in the texts of our times: experience and entertainment. Journal of Macromarketing, v. 20, p. 178-192, 2000. 
ICOM. ICOM statutes. 2007.

INSTITUTE OF MUSEUM AND LIBRARY SERVICES. Status of technology and digitization in the nation's museums and libraries, 2006.

ISO 9241-210. ISO 9241-210, Ergonomics of Human-system Interaction — Part 210: Humancentred Design for Interactive Systems, International Organization for Standardization, 2000.

ISOMAKI, $H$. The human modes of being in investigating user experience. In: SAARILUOMA, P.; ISOMAKI, H. (Eds.). . Future interaction design II. London: Springer-Verlag, 2009. p. 191-207.

JASHAPARA, Ashok (Ed.). Knowledge Management: An Integrated Approach. Harlow: FT Prentice Hall, 2004.

KAVAKLI, Evangelia; BAKOGIANNI, Sophia. Building museum information systems: a knowledge management approach. (E. Lipitakis, Ed.)Proceedings of the 6th Hellenic-European conference on computer mathematics and its applications. Anais...Athens: LEA Publishers, 2003

KIMMELMAN, Michael. Museums in a quandary: where are the ideals? New York Times, 2001.

KRIPPENDORFF, Klaus. Content analysis: an introduction to its methodology. Los Angeles: SAGE Publications, 2004.

LAVIE, Talia; TRACTINSKY, Noam. Assessing dimensions of perceived visual aesthetics of web sites. International Journal of Human-Computer Studies, v. 60, n. 3, p. 269-298, 2004.

LE COADIC, Yves-François. A ciência da informação. Brasília: Briquet de Lemos/Livros, 1996.

LEITÃO, João Filipe. Modernização administrativa e gestão da qualidade. Lisboa: Colibri, 2018.

MAGNANI, J. G. Cantor. Pensar grande o patrimônio cultural. Lua Nova, v. 3, n. 2. p. 62-67, 1986.

MAHLER, G. Quantum information. In: KORNWACHS, K.; JACOBY, K. (Eds.). . Information: new questions to a multidisciplinary concept. Berlin: Akademie Verlag, 1996. p. 103-118.

MAROEVIC, Ivo. The museum object as historical source and document. In: Museología e historia: un campo del conocimiento. [s.I.] ICOFOM Study Series, 2006.

MARQUES, Isabel. O Museu como Sistema de Informação. [Porto]: Universidade do Porto, 2010.

MARTY, P. The changing role of the museum webmaster: past, present, and future. (D. Bearman, J. Trant, Eds.)Museums and the Web 2004: Proceedings. Anais...Washington, D.C.: Archives \& Museum Informatics, 2004

MCCARTHY, J.; WRIGHT, P. Technology as experience. Interactions, v. 11, n. 5, p. 42-43, 2004.

MCHALE, J. El entorno cambiante de la información. Madrid: Tecnos, 1981. 
MENSCH, Peter Van. Methodological museology; or towards a theory of museum pratice. In: PEARCE, S. (Ed.). . Objects of knowledge. London: The Athlone Press, 1990. p. 141-157.

MILLER, Holmes. Managing customer expectations. Information System Management, v. 17, n. 2, p. $1-4,2000$.

MUELLER, Suzana; CAMPELLO, Bernadete; DIAS, Eduardo. Disseminação da pesquisa em ciência da informação e biblioteconomia no Brasil. Ciência da Informação, v. 25, n. 3, p. 1-22, 1996.

NITECKI, Danuta; WIGGINS, John; TURNER, Nancy. Assessment is not enough for libraries to be valued. Performance Measurement and Metrics, v. 16, n. 3, p. 197-210, 2015.

NORMAN, Don; MILLER, Jim; HENDERSON, Austin. What you see, some of what's in the future, and how we go about doing it. Conference companion on Human factors in computing systems - CHI '95, n. January, p. 155, 1995.

OTLET, Paul. Traité de documentation: le livre sur le livre: théorie et pratique. Bruxelas: Editiones Mundaneum, 1934.

PALLUD, Jessie; MONOD, Emmanuel. User experience of museum technologies: The phenomenological scales. European Journal of Information Systems, v. 19, n. 5, p. 562-580, 2010.

PALLUD, Jessie; STRAUB, Detmar W. Effective website design for experience-influenced environments: The case of high culture museums. Information and Management, v. 51, n. 3, p. 359-373, 2014.

PINHEIRO, Lena Vania Ribeiro. Pilares conceituais para mapeamento do território epistemológico da Ciência da Informação: disciplinaridade, interdisciplinaridade, transdisciplinaridade e aplicações. In: PINTO, V. B.; CAVALCANTE, L.; NETO, C. S. (Ed.). . Abordagens transdisciplinares da Ciência da Informação: gêneses e aplicações. Fortaleza: Edições UFC, 2007. p. 71-104.

PINHEIR0, Lena Vania Ribeiro. Confluências Interdisciplinares entre Ciência da Informação e Museologia. Museologia \& Interdisciplinaridade, v. 1, n. 1, p. 07-31, 2012.

PORIA, Yaniv; REICHEL, Arie; BIRAN, Avital. Heritage Site Perceptions and Motivations to Visit. Journal of Travel Research, v. 44, n. 3, p. 318-326, 2006.

PORTO, Mauro P. Muito além da informação: mídia, cidadania e o dilema democrático. São Paulo em Perspectiva, v. 12, n. 4, p. 17-25, 1998.

PORTUGAL. Decreto-Lei n.ํ 47/2004. D.R. Série A. 195 (19 de Ago. 2004), 2004.

RASCÃO, José. Da gestão estratégica à gestão estratégica da informação: como aumentar o tempo disponível para a tomada de decisão estratégica. Rio de Janeiro: E_papers, 2006.

RAYWARD, W. Boyd. The history and historiography of information science: Some reflections. Information Processing and Management, v. 32, n. 1, p. 3-17, 1996. 
ROWLEY, Jennifer. The wisdom hierarchy: Representations of the DIKW hierarchy. Journal of Information Science, v. 33, n. 2, p. 163-180, 2007.

SARACEVIC, Tefko. Ciência da informação: origem, evolução e relações. Perspectivas em Ciência da Informação, v. 1, n. 1, p. 41-62, 1996.

SCHRADER, Alvin. Toward a theory of library and information science. [s.I.] Indiana University, 1983.

SCHREINER, K. Basic paper. In: Collecting today for tomorrow. [s.I.] ICOFOM Study Series 6, 1984. p. 24-28.

SCHUMAKER, Robert P. From Data to Wisdom: The Progression of Computational Learning in Text Mining. Communications of the IIMA, v. 11, n. 1, p. 1-14, 2013.

SHANNON, Claude. A mathematical theory of communication. The Bell System Technical Journal, v. 27, n. July 1928, p. 379-423, 1948.

SHANNON, Claude; WEAVER, Warren. The mathematical theory of communication. [s.I.] The University of Illinois Press, 1963.

SHERA, J.; CLEVELAND, D. History and foundations of information-science. In:

WILLIAMS, M. (Ed.). . Annual Review of Information Science and Technology. New York: Knowledge Industries Publications (for the American Society of Information Science), 1979. v. 12p. 249-275.

SILVA, Armando Malheiro da. Arquívistica, biblioteconomia e museologia: do empirismo patrimonialista ao paradigma emergente da Ciência da Informação. I Congresso Internacional de Arquivos, Bibliotecas, Centros de Documentação e Museus. Anais...São Paulo: Imprensa Oficial do Estado, 2002.

SILVA, Armando Malheiro da. Documento e informação: as questões ontológica e epistemológica. Arquivo \& Administração, v. 4, n. 2, p. 5-32, 2005.

SILVA, Armando Malheiro da. A Informação: da compreensão do fenómeno e construção do objeto científico. Porto: Edições Afrontamento, 2006.

SILVA, Armando Malheiro da. Arquivologia e gestão da informação/conhecimento. Informação \& Sociedade: Estudos, v. 19, n. 2, p. 47-52, 2009a.

SILVA, Armando Malheiro da. Mediações e mediadores em Ciência da Informação. Prisma.Com, v. 9 , p. 68-104, 2009b.

SILVA, Carlos Guardado da. Prefácio. In: PACHECO, A.. Informação digital: o vértice comum entre a Diplomática e a Ciência da Informação. Vila Nova de Famalicão: Húmus, 2017. p. [9-10].

SILVA, Carlos Guardado da. Investigação em Ciência da Informação. Lisboa: Colibri, 2019. 
SILVA, Carlos Guardado da; CORUJO, Luis. Uma abordagem diacrónica da gestão da informação: conceito, enquadramento disciplinar, etapas e modelos. Ciência da Informação, v. 48, n. 2, p. 144164, 2019.

SILVA, Susana Gomes da. Enquadramento teórico para uma prática educativa nos museus. In: BARRIGA, S.; SILVA, S. G.. Serviços Educativos na Cultura. Porto: Setepés, 2007. p. 57-66.

SOLA, Tomislav. Reflections on a crucial problem for museums. In: SOFKA, V. (Ed.). . Museology and identity. [s.I.] ICOFOM Study Series 10, 1986. p. 15-18.

STRANSKY, Z. Metodologické otázky dokumentace soucasnoti. Muzeologicke Sesity, v. 5, p. 13-43, 1974.

THALLER, Manfred. A digital ivory tower: prolegomena for a computer science for historical studies. [S.I.]: Hypotheses, 24.04.2018.

TOST, Laia; ECONOMOU, Maria. Exploring the suitability of virtual reality interactivity for exhibitions through an integrated evaluation: the case of the Ename Museum. Museology Journal, University of the Aegean, v. 4, n. 1, p. 81-97, 2007.

VAKKARI, Pertti. Information seeking in context: a challenging metatheory. In: VAKKARI, P.;

SAVOLAINEN, R.; DERVIN, B. (Eds.). . Information seeking in Context. London: Taylor Graham, 1997. p. 451-446.

VALACICH, J.; PARBOTEEAH, D.; WELLS, J. The online consumer's hierarchy of needs.

Communication of the ACM 50, v. 50, n. 9, p. 84-90, 2007.

VICKERY, Brian. Information systems. London: Butterworths, 1973.

VON BERTALANFFY, Ludwig. General System Theory: foundations, development, applications. New York: George Braziller, 1968. v. 1

WATEREN, Jar Der. The importance of museum libraries. Inspel, v. 33, n. 4, p. 190-198, 1999.

ZINS, Chaim. Redefining information science: From "information science" to "knowledge science". Journal of Documentation, v. 62, n. 4, p. 447-461, 2006.

ZINS, Chaim. Conceptual approaches for defining data, information and knowledge. Journal of the American Society for Information Science and Technology, v. 58, n. 4, p. 479-493, 2007. 